\title{
Examining the factorial validity of the Quality of Life Scale
}

\author{
Ashley J. Reeves ${ }^{1}$, Russell T. Baker ${ }^{1 *} \mathbb{D}$, Madeline P. Casanova ${ }^{1}$, Scott W. Cheatham² and Michael A. Pickering ${ }^{1}$
}

\begin{abstract}
Background: Quality of life (QoL) is important to assess in patient care. Researchers have previously claimed validity of the Quality of Life Scale (QOLS) across multiple samples of individuals, but close inspection of results suggest further psychometric investigation of the instrument is warranted. Therefore, the purposes of this study were to: 1) evaluate the proposed five-factor, 15-item and three-factor, 16-item QOLS; 2 ) if the factor structure could not be confirmed, re-assess the QOLS using exploratory factor analysis (EFA) and covariance modeling to identify a parsimonious refinement of the QOLS structure for future investigation.

Methods: Participants varying in age, physical activity level, and identified medical condition(s) were recruited from clinical sites and ResearchMatch. Confirmatory factor analyses (CFA) were performed on the full sample $(n=1036)$ based on proposed 15- and 16-item QOLS versions. Subsequent EFA and covariance modeling was performed on a random subset of the data $\left(n_{1}=518\right)$ to identify a more parsimonious version of the QOLS. The psychometric properties of the newly proposed model were confirmed in the remaining half of participants $\left(n_{2}=518\right)$. Further examination of the scale psychometric properties was completed using invariance testing procedures across sex and health status sub-categories.

Results: Neither the 15- nor 16-item QOLS CFA met model fit recommendations. Subsequent EFA and covariance modeling analyses revealed a one-factor, five-item scale that satisfied contemporary statistical and model fit standards. Follow-up CFA confirmed the revised model structure; however, invariance testing requirements across sex and injury status subgroups were not met.

Conclusions: Neither the 15- nor 16-item QOLS exhibited psychometric attributes that support construct validity. Our analyses indicate a new, short-form model, might offer a more appropriate and parsimonious scale from some of the original QOLS items; however, invariance testing across sex and injury status suggested the psychometric properties still vary between sub-groups. Given the scale design concerns and the results of this study, developing a new instrument, or identifying a different, better validated instrument to assess $\mathrm{QoL}$ in research and practice is recommended.
\end{abstract}

Keywords: Exploratory factor analysis, Confirmatory factor analysis, Covariance modeling, Instrument development, Physically active, Healthcare, Well-being

\section{Background}

Assessing patient reported outcomes through a multidimensional lens (e.g., patient symptomatology, functional status, quality of life, etc.) is an important component of healthcare research and practice [1]. Quality of life (QoL), which may date back to Aristotle [2], is a longstanding and valued construct assessed in patient care

\footnotetext{
* Correspondence: russellb@uidaho.edu

'University of Idaho, 875 Perimeter Drive MS2401, Moscow, ID 83844, USA Full list of author information is available at the end of the article
}

and intervention research [3]. According to existing literature, QoL may include a variety of factors, including life satisfaction $[4,5]$, disease- or condition-specific symptoms [6], mood, and functional status [1, 7]. The multi-faceted concept of QoL, coupled with a lack of agreement on what it should entail, limit its usefulness in informing patient care decisions, despite its importance.

Inconsistently applied definitions of QoL, particularly in health care fields, make it difficult to accurately and

(c) The Author(s). 2020 Open Access This article is distributed under the terms of the Creative Commons Attribution 4.0 International License (http://creativecommons.org/licenses/by/4.0/), which permits unrestricted use, distribution, and 
consistently assess $[1,8]$. For example, Gill and Feinstein (1994) examined 75 studies with 159 QoL instruments and identified a lack of coherence in meaning between many of the instruments [9]. Along with a lack of clarity on a definition, the notion that ill or injured individuals perceive QoL differently than healthy individuals adds to the confusion. This belief, however, is not well supported in the literature $[1,7,8,10]$. Individuals, regardless of health or injury status, recognize and respond to the same QoL factors; however, the relative importance of these factors (e.g., functional impairments) can vary across the lifespan or by specific situations $[1,7]$. Therefore, when assessing the effectiveness of provided patient care services, healthcare providers should recognize that physical health status is only one of the factors affecting an individual's overall QoL $[1,8]$.

Given the lack of clarity, there is a need for QoL scales to be consistent and meaningful to most individuals [8]. Instruments should be psychometrically sound and assess appropriate dimensions of QoL without blending with other related, but distinct health constructs (e.g., functional performance) [1]. One commonly used instrument is the Flanagan Quality of Life Scale (QOLS). The original QOLS consisted of fifteen items and was intended to measure five different aspects (i.e. "factors") of QoL: 1) physical and material well-being (PMWB), 2) relations with other people (REL), 3) social, community, and civic activities (SCC), 4) personal development and fulfillment (PDF), and 5) recreation (REC) [8]. A modified version of the QOLS was developed for use with chronically ill patients (e.g., fibromyalgia, cardiac disease, arthritis, posttraumatic stress disorder, diabetes, etc.), by adding a sixteenth item to assess independence. The 16-item version is more commonly used than the 15-item version [8] and aimed to assess three distinct factors of QoL: 1) relationships and material well-being (RMW), 2) personal, social, and community commitment (PSCC), and 3) health and functioning (HF) [10]. For both versions of the QOLS, individuals score items using a 1 ("terrible") to 7 ("delighted") point Likert scale. The QOLS has been studied in healthy populations, chronic illness groups, and adults of all ages $[8,10-15]$. It has not, however, been studied in children, and therefore, is not currently recommended for use in youth populations [8].

Although the QOLS has been suggested to be a reliable and valid scale [10-15], psychometric findings have been inconsistent, and frequently fail to meet recommended guidelines for establishing scale validity $[16,17]$ (Tables 1 \& 2). In addition, across multiple studies with

Table 1 Exploratory factor analysis solutions for the QOLS items from Burckhardt, et al. (2003) $)^{10}$

\begin{tabular}{|c|c|c|c|c|c|}
\hline Subjects & Sample 1 & Sample 2 & Sample 3 & Sample 4 & Sample 5 \\
\hline Item $^{10}$ & Factor & Factor & Factor & Factor & Factor \\
\hline 1. "Material comforts home, food, conveniences, financial security..." & HF & $\mathrm{RMW}^{*}$ & RMW & DNF & RMW \\
\hline 2. "Health - being physically fit and vigorous..." & HF & HF & $\mathrm{HF}$ & $\mathrm{HF}$ & HF \\
\hline $\begin{array}{l}\text { 3. "Relationships with parents, siblings \& other relatives - } \\
\text { communicating, visiting, helping..." }\end{array}$ & $\mathrm{RMW}^{*}$ & RMW & PSCC\# & RMW & RMW \\
\hline 4. "Having and raising children..." & RMW & RMW & $\mathrm{RMW}^{*}$ & RMW & RMW \\
\hline 5. "Relationships with spouse or significant other..." & $\mathrm{RMW}^{*}$ & RMW & RMW & RMW & RMW \\
\hline 6. "Close friends..." & RMW & $\mathrm{RMW}^{*}$ & $\mathrm{RMW}^{*}$ & RMW & $\mathrm{RMW}^{*}$ \\
\hline 7. "Helping and encouraging others, volunteering, giving advice..." & PSCC\# & PSCC & PSCC $^{*}$ & PSCC & PSCC \\
\hline 8. "Participating in organizations and public affairs..." & PSCC & PSCC & PSCC & PSCC & PSCC \\
\hline $\begin{array}{l}\text { 9. "Learning - attending school, improving understanding, } \\
\text { getting additional knowledge..." }\end{array}$ & PSCC & PSCC & PSCC & PSCC & PSCC \\
\hline $\begin{array}{l}\text { 10. "Understanding yourself - knowing your assets and limitations - } \\
\text { knowing what life is about..." }\end{array}$ & PSCC\$ & PSCC & PSCC & PSCC & PSCC \\
\hline 11. "Work - job or in home..." & HF & HF & $\mathrm{HF}$ & $\mathrm{HF}$ & $H F^{*}$ \\
\hline 12. "Expressing yourself creatively..." & PSCC & PSCC & PSCC $^{*}$ & PSCC & PSCC \\
\hline 13. "Socializing - meeting other people, doing things, parties, etc." & RMW & $\mathrm{PSCC}^{*}$ & $\mathrm{PSCC}^{*}$ & HF\# & PSCC\$ \\
\hline 14. "Reading, listening to music, or observing entertainment..." & $\mathrm{RMW}^{*}$ & PSCC & PSCC & DNF & PSCC \\
\hline 15. "Participating in active recreation..." & $\mathrm{HF}$ & HF & HF & $\mathrm{HF}$ & HF \\
\hline 16. "Independence, doing for yourself..." & NI & NI & NI & $\mathrm{HF}$ & HF \\
\hline
\end{tabular}

RMW Relationships and Material Well-being; PSCC Personal, Social, and Community Commitment; HF Health and Functioning; NI Item Not Included in Analysis; DNF Item Did Not Factor; ${ }^{*}=$ Item had substantial cross-loading (i.e., $\geq .30$, but $\leq .44$ ) on another factor; \# = Item had extreme cross-loading (i.e., $\geq .45$ ) on another factor. $\$=$ Item had substantial cross-loadings (i.e., $\geq .30$ ) on two other factors. Sample $1=319$ healthy Swedish and American individuals; Sample $2=584$ Americans with chronic illness; Sample 3=170 Swedish women with chronic rheumatic disease; Sample $4=353$ men; Sample $5=888$ women. Each item is labeled in the proposed construct from that paper 
Table 2 Exploratory factor analysis solutions across studies validating the Flanagan Quality of Life Scale

\begin{tabular}{|c|c|c|c|}
\hline Subjects & Sample 1 & Sample 2 & Sample 3 \\
\hline Item & Factor & Factor & Factor \\
\hline 1. Material comforts home, food, conveniences, financial security... & RMW & PWSB* & MWBPD* \\
\hline 2. Health - being physically fit and vigorous... & $\mathrm{HF}$ & AP & PSCC* $^{*}$ \\
\hline 3. Relationships with parents, siblings \& other relatives - communicating, visiting, helping... & RMW & $\mathrm{RO}$ & $\mathbb{R}$ \\
\hline 4. Having and raising children... & RMW & $\mathrm{RO}$ & $\mathbb{R}$ \\
\hline 5. Relationships with spouse or significant other... & RMW & $\mathrm{RO}$ & $\mathbb{R}^{*}$ \\
\hline 6. Close friends... & RMW & $\mathrm{RO}$ & $\mathbb{R}$ \\
\hline 7. Helping and encouraging others, volunteering, giving advice... & PSCC & PWSB* & $\mathbb{R}$ \\
\hline 8. Participating in organizations and public affairs.. & PSCC & PWSB & PSCC $^{*}$ \\
\hline 9. Learning - attending school, improving understanding, getting additional knowledge... & PSCC & PWSB & PSCC \\
\hline 10. Understanding yourself - knowing your assets and limitations - knowing what life is about.. & PSCC! & PWSB & MWBPD \\
\hline 11. Work - job or in home... & $\mathrm{HF}$ & $A P^{*}$ & MWBPD \\
\hline 12. Expressing yourself creatively... & PSCC & PWSB & MWBPD \\
\hline 13. Socializing - meeting other people, doing things, parties, etc..... & PSCC & PWSB\$ & PSCC $^{*}$ \\
\hline 14. Reading, listening to music, or observing entertainment... & PSCC & PWSB\$ & PSCC $^{*}$ \\
\hline 15. Participating in active recreation... & $\mathrm{HF}$ & AP & PSCC $^{*}$ \\
\hline 16. Independence, doing for yourself... & $\mathrm{HF}$ & AP & MWBPD\# \\
\hline
\end{tabular}

Factor Names: RMW Relationships and Material Well-being; PSCC Personal, Social, and Community Commitment; HF Health and Functioning; PSWB Personal and Social Well-being; $R O$ Relationship with Others; AP Active Participation; MWBPD Material Well-being and Personal Development; $I R$ Interpersonal relationships. Other Abbreviations and Symbols: NI Item Not Included in Analysis; DNF Item Did Not Factor; ${ }^{*}=$ Item had substantial cross-loading (i.e., $\geq .30$, but $\leq .44$ ) on another factor; \# = Item had extreme cross-loading (i.e., $\geq .45$ ) on another factor. $\$=$ Item had substantial cross-loadings (i.e., $\geq .30$ ) on two other factors; $\wedge=$ authors did not provide cross-loading values; = Item in factor but loading was less than .35. Sample $1=140$ Spanish women with fibromyalgia(15); Sample $2=113$ Swedish women with fibromyalgia(12); Sample $3=146$ German patients with fibromyalgia(14)

diverse samples, published factor structures have varied [10-15] (Tables 1 \& 2) and do not meet recommended guidelines $[16,18]$. For example, findings in most studies of the original 15-item version are inconsistent with the originally proposed five-factor structure [10-15], which indicates the theoretical framework of the scale is not well-supported. Similarly, studies using the 16-item QOLS have found that items typically factor into three dimensions [10-15], however, the specific factor makeup (e.g., using the same items within dimensions), has varied (Tables $1 \& 2$ ). Studies have also attempted to assess internal consistency, test-retest reliability, validity of the scale presented in different languages, and concurrent validity with other instruments [10-15], but these results must be interpreted carefully due to the lack of a consistent factor structure. Thus, further investigation of the psychometric properties of the scale is warranted.

In short, factorial validity and consistency of the scale across populations is not well-supported [10-15] (Tables 1 \& 2). Further, at least three additional steps beyond EFA are necessary to establish that a version of the QOLS is sound for use in practice and research. These include: 1) EFA re-analysis to identify items with a more consistent factor structure, 2) confirmatory factor analysis (CFA) to more rigorously examine the structure and, 3) CFA-based invariance testing to explore measurement properties of the scale across subgroups of the population (e.g., gender, age, disease types, etc.) $[16,17]$. Failure to establish equivalent measurement properties across groups risks introducing measurement bias, which confounds interpretation between group comparisons $[16,18]$.

A systematic CFA approach, subsequent to identifying a meaningful factor structure via EFA, offers a more complete and rigorous psychometric examination of an instrument's measurement properties. Completing an invariance analysis facilitates logical refinement and stricter testing of its measurement properties [17-19]. Invariance testing of the QOLS would ensure that the operationalization of the construct 'quality of life' has the same meaning across groups. Ultimately, through this process, a more psychometrically sound instrument can be identified [16, 18]. Currently, psychometric analysis involving EFA refinement, followed by CFA and invariance testing, has not been conducted on the QOLS. Additionally, the scale has not yet been assessed in a group of participants defined as "physically active," or across participants who are suffering from various stages (i.e., acute, sub-acute, and chronic) of musculoskeletal injury. 
Despite the scale being used for over 40 years, the incomplete psychometric analysis of the QOLS is insufficient to justify widespread use. Therefore, the purposes of this study were to: 1) assess the factorial validity of the five-factor, 15-item and the three-factor, 16-item QOLS, and if these scales met model fit recommendations, 2) to assess measurement (i.e., equal forms, loadings, and intercepts) and structural (i.e., equal factor variances/ covariances, and equal means) invariance of the QOLS across gender and physical health status (i.e., physically active-healthy, physically active-injured, musculoskeletal pathology with a comorbidity, and osteoarthritis). A secondary purpose, if model fit did not hold or invariance testing could not be completed, was to: 1 ) re-examine the factor structure of the QOLS using an EFA and covariance modeling approach to identify a more parsimonious version of the QOLS for future investigation, 2) assess the newly proposed covariance QOLS model using CFA procedures, and if the new model met fit recommendations, 3) assess measurement and structural invariance of the revised QOLs across gender and health status.

\section{Methods}

The present study was approved by University Institutional Review Board (IRB). Informed consent was obtained from all participants before data collection. Data were collected over the course of one year from various settings across the nation. Confidentiality of participant responses was ensured per the approved IRB protocol, and all data were deidentified prior to analysis.

\section{Participants}

Adult participants were recruited from several locations across the nation to obtain a large heterogeneous sample that included different ages, physical activity levels, and medical conditions. Individuals were either recruited from: 1$)$ athletic training clinics $(n=22), 2)$ outpatient rehabilitation clinics $(\mathrm{n}=2$; i.e., physically active individuals), or 3) ResearchMatch $(n=316$; Vanderbilt University, Nashville, TN), a nationwide online database of research volunteers. Individuals who were physically active and classified as healthy or having an acute, subacute, or persistent injury were included in the study (Table 3). Individuals with chronic pain were excluded

Table 3 Study definitions and terminology

\begin{tabular}{|c|c|}
\hline Terminology & Definition \\
\hline Physically Active 20 & $\begin{array}{l}\text { "An individual who engages in athletic, recreational, or occupational activities that require } \\
\text { physical skills and who uses strength, power, endurance, speed, flexibility, range of motion, } \\
\text { or agility at least } 3 \text { days per week." }\end{array}$ \\
\hline \multicolumn{2}{|l|}{ Injury Classification ${ }^{20}$} \\
\hline Healthy & "Free from musculoskeletal injury and fully able to participate in sport or activity." \\
\hline Acute Injury & $\begin{array}{l}\text { "A musculoskeletal injury that precludes full participation in sport or activity for at least } 2 \\
\text { consecutive days (0-72 h post-injury)." }\end{array}$ \\
\hline Subacute Injury & $\begin{array}{l}\text { "A musculoskeletal injury that precludes full participation in sport or activity for at least } 2 \\
\text { consecutive days ( } 3 \text { days to 1-month post-injury)." }\end{array}$ \\
\hline Persistent Injury & "A musculoskeletal injury that has been symptomatic for at least 1 month." \\
\hline Chronic Injury & "Pain that consistently does not get any better with routine treatment or non-narcotic medication." \\
\hline \multicolumn{2}{|c|}{ Activity Level Classification ${ }^{22}$} \\
\hline Inactive & "No activity beyond baseline activity." \\
\hline Low & "Activity beyond baseline, but fewer than 150 min of moderate intensity exercise per week." \\
\hline Medium & "150-300 min of moderate intensity activity per week". \\
\hline High & "More than 300 min of moderate intensity activity per week." \\
\hline \multicolumn{2}{|l|}{ Athlete Level ${ }^{20}$} \\
\hline Competitive Athlete & $\begin{array}{l}\text { "A participant who engages in a sport activity that requires at least } 1 \text { pre-participation examination, } \\
\text { regular attendance at scheduled practices and/or conditioning sessions and a coach who leads } \\
\text { practices and/or competitions." }\end{array}$ \\
\hline Recreational Athlete & $\begin{array}{l}\text { "Participants who meet the criteria for physical activity and participate in sport, but do not meet } \\
\text { the criteria for competitive status." }\end{array}$ \\
\hline Occupational Athlete & $\begin{array}{l}\text { "Participants who meet the criteria for physical activity for occupation or recreation, but do not } \\
\text { meet the criteria for competitive or recreational athlete." }\end{array}$ \\
\hline Physically Active in ADLs & $\begin{array}{l}\text { "Participants who do not meet the criteria for any "athlete" category, but who are physically active } \\
\text { through their daily activities (e.g., physically active for at least } 30 \text { min per day, } 3 \text { days per week)." }\end{array}$ \\
\hline
\end{tabular}

$A D L$ Activities of daily living. Definitions for physically active, injury classifications, and athlete level are from Vela and Denegar (2010). ${ }^{20}$ Activity level definitions are from the US Department of Health and Human Services ${ }^{22}$ 
from the study as chronic pain has unpredictable patterns $[20,21]$. Volunteers registered on ResearchMatch provide information about their health status and other pieces of personal or demographic information and are then randomly selected based on study criteria. For the present study, individuals recruited through ResearchMatch, were eligible to participate if they had either: 1) a musculoskeletal pathology with a comorbidity, or 2) osteoarthritis. Data from ResearchMatch contained identifiers to allow the survey to be email to participants, but the collected data were de-identified prior to analysis and all files containing respondent identifying information were deleted.

From the total sample, individuals were also split into four different subgroups: 1) physically active healthy (PA-H), 2) physically active injured (PA-I), 3) musculoskeletal pathology with a comorbidity (MSK-C), and 4) osteoarthritis (OA). These subgroups were chosen to facilitate comparison across studies based on previous literature assessing factor structure of the QOLS [10]. Individuals in the PA-H and PA-I groups were classified based on a priori definitions used in previous literature (Table 3) [20]. Classifications included injury category (i.e., acute, subacute, persistent) and type of athlete (i.e., competitive, recreational, occupational, or physically active in activities of daily living [ADL]; Table 3) [20]. Individuals in all groups were also classified into one of four possible "activity levels" (i.e., inactive, low, medium, high; Table 3), as defined by the US Department of Health and Human Services [22].

\section{Instrumentation}

A survey was created in paper and electronic form. The electronic survey was created using Qualtrics online software (Qualtrics, LLC, Provo, UT), with all paper responses also being input into Qualtrics for data analysis. Information collected was identical in both versions of the survey, and included basic demographics (e.g., age, sex, physical activity level, etc.) and the QOLS.

\section{Quality of Life Scale}

The QOLS is an instrument created based on commonly identified factors that may pertain to QoL [8]. Both a 15- and 16-item version exist and have been studied in various populations [10-15]. The 16-item version includes all items in the 15-item version and the addition of one item aimed at evaluating independence as it pertains to one's QoL [10]. Participants responded to the 16-item QOLS using a 7-point Likert scale, with 1 representing "terrible" and 7 representing "delighted" [8]. Item scores are summed together, with lower scores indicating poorer quality of life and higher scores indicating better quality of life [8].

\section{Data analysis}

Data was initially analyzed using CFA maximum likelihood estimation procedures for both the 15- and 16-item QOLS. Because model fit did not meet recommended guidelines as outlined in the literature [16, 17], the data was then split randomly into two halves $\left(\mathrm{n}_{1}, \mathrm{n}_{2}\right)$ with 518 participants in each sample. An EFA was conducted using the $\mathrm{n}_{1}$ sample to identify a more parsimonious and psychometrically sound solution. The $n_{1}$ sample was also used to test the model using a more rigorous covariance model approach based on the final EFA solution. The covariance model was then confirmed using CFA with sample $\mathrm{n}_{2}$. Lastly, invariance testing using the full sample (i.e., $\mathrm{n}_{1}$ and $\mathrm{n}_{2}$ combined) was conducted to assess measurement and structural invariance of the QOLs across gender (i.e., male, female) and health status (i.e., PA-H, PA-I, OA). Finally, a covariance model latent variable correlation analysis and a composite score bivariate correlational analysis were conducted to determine if the modified version of the scale explained an acceptable percentage of the variance in responses on the original QOLS.

\section{Data cleaning}

Data was exported from Qualtrics, and all analyses were conducted in Statistical Package for Social Sciences Version 24.0 (IBM Corp., Armonk, NY). Data was treated conservatively, and any participants missing more than $10 \%$ of the responses on the QOLS (i.e., 2 or more missing responses) were excluded from analysis. Remaining missing data was replaced with the rounded mean score of the respective item for analysis purposes. Participants with missing demographic data were not excluded from analysis. Data was assessed for normality using histograms, z-scores, and skewness and kurtosis values. Possible multivariate outliers were also identified using Malahanobis distance, for which the cut-off value for 16 degrees of freedom at a $p$-value of .001 was 39.252 [17].

\section{Confirmatory factor analysis of the 15- and 16-item Quality of Life Scale}

The full sample was used to conduct a CFA using maximum likelihood estimation in Analysis of Moment Structures (AMOS) software (IBM Corp., Armonk, NY) on both the 15-item and 16-item scales. Responses for the original fifteen items were pulled from the full data set of sixteen items to examine the five-factor structure. Subsequently, the proposed three-factor, 16-item version was assessed using responses to all sixteen items. In order to assess correlations between the five-factor and three-factor latent constructs, additional first-order CFA's were conducted on the 15 and 16-item QOLS. Model fit indices were evaluated based on a priori values 
to evaluate the originally proposed factor structures. The relative goodness-of-fit indices computed were the Comparative Fit Index (CFI; $\geq .95$ ), Tucker-Lewis Index (TLI; $\geq$.95), Root Mean Square Error of Approximation (RMSEA $\leq .06$ ), and Bollen's Incremental Fit Index (IFI; $\geq .95)[16,17,23]$. The likelihood ratio statistic (Chi square or CMIN) was also assessed, but because it is heavily influenced by sample size, it was not used as the primary assessment of model fit $[17,19]$. If model fit criteria were met, invariance testing was to be applied to the sample. Since model fit criteria were not met, EFA, covariance modeling, CFA, and invariance procedures were conducted to assess for a more valid revised factor structure.

\section{Identification of a modified Quality of Life Scale}

The full sample was randomly split in half (i.e., Samples $\mathrm{n}_{1}$ and $\mathrm{n}_{2}$ ). Sample $\mathrm{n}_{1}$ was re-analyzed using EFA. EFA was conducted using maximum likelihood extraction; Bartlett's test for sphericity and KMO for sampling adequacy were both assessed for violations. Cut-off values were set a priori at $<.001$ for Bartlett's test of sphericity and $\geq .80$ for $\mathrm{KMO}$, which are conservative compared to widely accepted values (KMO >.70, Bartlett's <.05) [18]. Items with loadings less than .40 were removed, followed by items that cross-loaded on multiple factors at .30 or greater [18]. Items with loadings less than .30 were classified as "Did Not Factor" (DNF), and those with loadings less than .40 were classified as "Did Not Load" (DNL). For analysis purposes, cross loadings were defined as substantial $(\geq .30 \leq .44)$ or extreme $(\geq .45)$.

Bivariate correlations between items, Cronbach's alpha, and the concept each item was intended to measure were used to make removal decisions. Both Cronbach's alpha and omega were used to estimate internal consistency $[18,24]$. Cronbach's alpha was set a priori as $\geq .70$ and $\leq .89$ [18]. Items were removed one at a time, and the EFA and Cronbach's alpha were re-run after the removal of each item. This process continued until a parsimonious factor structure that met recommended statistical guidelines was met.

\section{Validation analysis of the modified Quality of Life Scale}

The modified QOL scale identified during the EFA process was then re-assessed based on a more restricted covariance modeling specifying no cross loadings, using sample $n_{1}$. The same criteria utilized for the initial CFA were used to assess model fit $[17,19]$. The model was then confirmed via CFA using sample $\mathrm{n}_{2}$. Following confirmation of the new model invariance testing with the full sample was conducted to assess measurement and structural invariance of the modified QOLS across sex (i.e., male, female) and health status (i.e., physically active-healthy, physically active-injured, and osteoarthritis). Invariance testing ensures that across groups, factors (e.g., relationships and material well-being, personal, social, and community commitment, etc.) have identical items, the meaning of those factors are similar, and that the means of the factors can be meaningfully compared [17, 19]. Invariance was evaluated based on a CFI difference $\left(\mathrm{CFI}_{\mathrm{DIFF}}\right)$ of less than .01 , and the chisquare difference test $\left(\chi_{\text {DIFF }}^{2}\right)$, with a $p$-value cut-off of $0.01[17,19]$. Given the sensitivity of the $\chi^{2}$ DIFF test to sample size, the $\mathrm{CFI}_{\text {DIFF }}$ test held greater weight in decisions regarding invariance testing model fit.

\section{Correlation analyses}

The total sample was used to assess the relationship between participant scores on the 16-item QOLS and the newly proposed modified QOLS. A covariance modeling approach was used to assess correlations using latent variable scores. Additionally, a bivariate correlation analysis was conducted using the cumulative scores from the 16-item scale and the cumulative scores on the newly proposed QOLS. An acceptable percentage of the variance explained was set at $r \geq 0.90\left(R^{2}=0.81\right)$ [25].

\section{Results}

Data cleaning \& sample characteristics

A total of 1098 individuals completed the QOLS. In the sample, 64 (6.1\%) individuals were missing a response to one item; the items with missing responses were replaced with the rounded mean of the respective item. Of the 1098 individuals with one or fewer missing responses on the QOLS, a total of 57 participants (5.2\%) were identified as possible multivariate outliers and were removed from the final analysis. Five additional participants, who were part of the PA-H and PA-I subgroups, were excluded because injury category was not specified, and therefore, could not be classified into either the healthy or injured group. This left a total of 1036 individuals, ages 18-74 years old, in the final analysis for the full sample. The full sample was broken down into the following subgroups: PA-H $(n=151,18-61$ y), PA-I ( $n$ $=470,18-74 \mathrm{y})$, MSK-C $(n=279,19-65 \mathrm{y})$, and OA $(n$ $=127,27-65$ y). Demographic information for the full sample and each subgroup is provided in Table 4.

\section{Physically active healthy and physically active injured}

Beyond the demographic information provided in Table 4 , individuals in the physically active groups were also classified by level of competition within their respective sport based on definitions used in previous literature (Table 3) [20]. Individuals participated in a variety of sports and activities, adding to the heterogeneity of the sample. In the injured group, the most common sports or activities were soccer $(n=50,10.6 \%)$, basketball ( $n=$ $48,10.2 \%)$, and track and field ( $n=47,10.0 \%)$. In the 
Table 4 Demographic information across samples

\begin{tabular}{|c|c|c|c|c|c|}
\hline & $\begin{array}{l}\text { Full Sample } \\
(n=1036)\end{array}$ & $\begin{array}{l}\text { Physically Active - } \\
\text { Healthy }(n=151)\end{array}$ & $\begin{array}{l}\text { Physically Active - } \\
\text { Injured }(n=470)\end{array}$ & $\begin{array}{l}\text { Musculoskeletal Pain \& } \\
\text { Comorbidity }(n=284)\end{array}$ & $\begin{array}{l}\text { Osteoarthritis } \\
(n=131)\end{array}$ \\
\hline \multicolumn{6}{|l|}{ Sex } \\
\hline Male & $387(37.4)$ & $82(54.3)$ & $240(51.1)$ & $44(15.5)$ & $21(16.0)$ \\
\hline Female & $641(61.9)$ & $69(45.7)$ & $229(48.7)$ & $236(83.1)$ & $107(81.7)$ \\
\hline Other & $3(0.3)$ & $0(0.0)$ & $0(0.0)$ & $2(0.7)$ & $1(0.8)$ \\
\hline Unknown & $5(0.5)$ & $0(0.0)$ & $1(0.2)$ & $2(0.7)$ & $2(1.5)$ \\
\hline Age (years) & $33.87 \pm 15.73$ & $24.28 \pm 8.18$ & $24.28 \pm 9.48$ & $46.07 \pm 12.10$ & $53.93 \pm 9.37$ \\
\hline \multicolumn{6}{|c|}{ Activity Level ${ }^{21}$} \\
\hline Inactive & $142(13.7)$ & $3(2.0)$ & $31(6.6)$ & $81(28.5)$ & $27(20.6)$ \\
\hline Low & $294(28.4)$ & $16(10.6)$ & 89 (18.9) & $126(44.4)$ & $63(48.1)$ \\
\hline Medium & $291(28.1)$ & $53(35.1)$ & $146(31.1)$ & $61(21.5)$ & $31(23.7)$ \\
\hline High & $302(29.2)$ & $78(51.7)$ & $203(43.2)$ & $13(4.6)$ & $8(6.1)$ \\
\hline Unknown & $7(0.7)$ & $1(0.7)$ & $1(0.2)$ & $3(1.1)$ & $2(1.5)$ \\
\hline
\end{tabular}

Data is presented as number of individuals (\% of total in sample). Age is given as mean \pm SD. Activity levels are based on definitions of the US Department of Health and Human Services ${ }^{21}$

healthy group, soccer $(n=17,11.3 \%)$ and football $(n=13,8.6 \%)$ were the most common. Information on classification and sport participation are presented in Table 5 [20]. Further classification of the injured individuals revealed that $217(49.2 \%)$ had a persistent injury, $124(26.4 \%)$ had an acute injury, and 129 (27.4\%) had a subacute injury based on the definitions provided in Table 3 [20].

\section{Confirmatory factor analysis five-factor 15-item Quality of Life Scale}

The CFA of the five-factor, 15-item QOLS indicated marginal, but not preferred model fit to the sample data. The goodness-of-fit indices approached but did not meet recommended values $(\mathrm{CFI}=.930, \mathrm{TLI}=.913$, RMSEA $=$ .098 , IFI = .930; Fig. 1). Moreover, correlations between first-order latent variables (e.g., 'Material Well-Being, 'Relationships', etc.) were very high, ranging from $\mathrm{r}=.81$ to $r=.96$ (Fig. 2).

\section{Confirmatory factor analysis three-factor 16-item Quality of Life Scale}

The CFA of the three-factor, 16-item QOLS also indicated marginal, not preferred model fit. The goodness-of-fit indices approached but did not meet recommended values $(\mathrm{CFI}=.931$, TLI $=.918$, RMSEA $=.093, \mathrm{IFI}=.931$; Fig. 3). Correlation values between all three first-order latent variables were high $(\mathrm{r}=.91)$ (Fig. 4).

\section{Scale structure of modified Quality of Life Scale Identification of a modified Quality of Life Scale} Initial EFA of the QOLS using sample $\mathrm{n}_{1}(n=518)$ extracted two dimensions (Table 6). Items 4,5 , and 15
Table 5 Classification of physically active individuals

\begin{tabular}{|c|c|c|}
\hline & $\begin{array}{l}\text { Physically Active - } \\
\text { Healthy }(n=151)\end{array}$ & $\begin{array}{l}\text { Physically Active - } \\
\text { Injured }(n=470)\end{array}$ \\
\hline \multicolumn{3}{|l|}{ Athlete Type ${ }^{20}$} \\
\hline Competitive & $75(49.7)$ & $290(61.7)$ \\
\hline Recreational & $34(22.5)$ & $63(13.4)$ \\
\hline Occupational & $11(7.3)$ & $55(11.7)$ \\
\hline Activities of Daily Living & $25(16.6)$ & $61(13.0)$ \\
\hline Unknown & $6(4.0)$ & $1(0.2)$ \\
\hline \multicolumn{3}{|l|}{ Sport } \\
\hline Baseball & $6(4.0)$ & $33(7.0)$ \\
\hline Basketball & $10(6.6)$ & $48(10.2)$ \\
\hline Cheerleading & $1(0.7)$ & $7(1.5)$ \\
\hline Cross Country & $2(1.3)$ & $3(0.6)$ \\
\hline Football & $13(8.6)$ & $32(6.8)$ \\
\hline Racquet Sports & $3(2.0)$ & $5(1.1)$ \\
\hline Recreational Running & $9(6.0)$ & $7(1.5)$ \\
\hline Soccer & $17(11.3)$ & $50(10.6)$ \\
\hline Softball & $8(5.3)$ & $41(8.7)$ \\
\hline Swim and Dive & $1(0.7)$ & $9(1.9)$ \\
\hline Track and Field & $6(4.0)$ & $47(10.0)$ \\
\hline Volleyball & $3(2.0)$ & $12(2.6)$ \\
\hline Weight Lifting & $12(7.9)$ & $22(4.7)$ \\
\hline Other & 29 (19.2) & $82(17.4)$ \\
\hline No Sport Participation & $24(15.9)$ & $70(14.9)$ \\
\hline Unknown & $7(4.6)$ & $2(0.4)$ \\
\hline
\end{tabular}




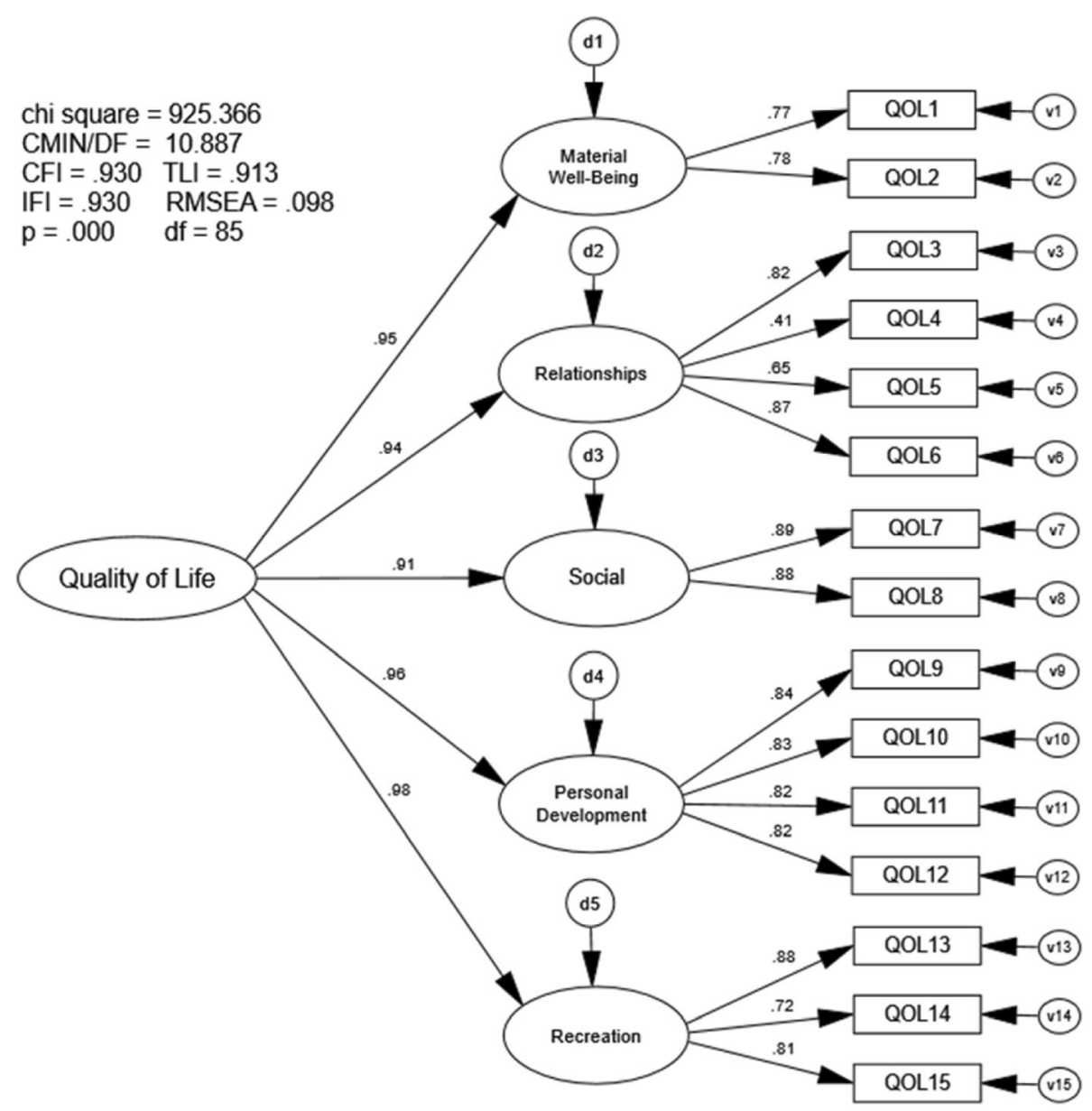

Fig. 1 Confirmatory Factor Analysis five-factor 15-item QOLS. Chi Sq = Chi Square (X2), CMIN/DF = the X2 / degrees of freedom ratio; CFI = Comparative Fit Index; TLI = Tucker-Lewis Index; IFI = Bollen's Incremental Fit Index; RMSEA = Root Mean Square Error of Approximation, $\mathrm{df}=$ degrees of freedom, $p=$ alpha level

were eliminated due to low loadings or high cross loadings. Items $6,7,9,10,12,13,14,16$ were removed due to inflated Cronbach's alpha levels, high correlation values, or lack of conceptual relevance (i.e. rearing children) to certain groups in the population. The resulting single-factor, five-item scale consisted of items 1, 2, 3, 8, and 11 from the original 16-item QOLS. The single factor accounted for $58.9 \%$ of the variance in the five retained items, with all item loadings $\geq .75$. Cronbach's alpha and omega $=.89$ (Table 7$)$. This brief version of the QOLS better satisfied a priori statistical guidelines.

\section{Validation analysis of the modified Quality of Life Scale}

Covariance modeling of the modified QOLS using sample $\mathrm{n}_{1}$ indicated good model fit $\left(\mathrm{X}^{2}[5]=16.845, p \leq\right.$ .005 ; CFI $=.992$; RMSEA $=.068$; Fig. 5 ). The majority of fit indices values exceeded recommended values, while RMSEA levels approached the highest recommended levels. All factor loadings were significant $(p \leq .001)$, and modification indices did not suggest model fit could be substantially improved with the specification of any nonzero covariances between error terms.

\section{Confirmatory factor analysis of modified Quality of Life Scale}

Confirmatory factor analysis using sample $\mathrm{n}_{2}$ also indicated very good model fit. All of the fit indices calculated exceeded recommended values $\left(\chi^{2}[5]=5.44\right.$, $p=.365$; CFI $=1.0$; RMSEA $=.013$; Fig. 6$)$. All itemfactor loadings were statistically significant $(p \leq .001)$ and ranged from .73 to .80 .

\section{Invariance testing for sex subgroups}

From the full sample, males $(n=387)$ and females $(n=$ $641)$ were used for invariance testing. The initial configural model demonstrated very good model fit (CFI = .994; $X^{2}=23.245 ;$ RMSEA $=.036$; Table 8), indicating the form of a basic five-item model structure was invariant across sex. The metric model (i.e., equal loadings) also passed both the $\mathrm{CFI}_{\text {DIFF }}$ test and the $\mathrm{X}_{\text {DIFF }}^{2}$ test. 


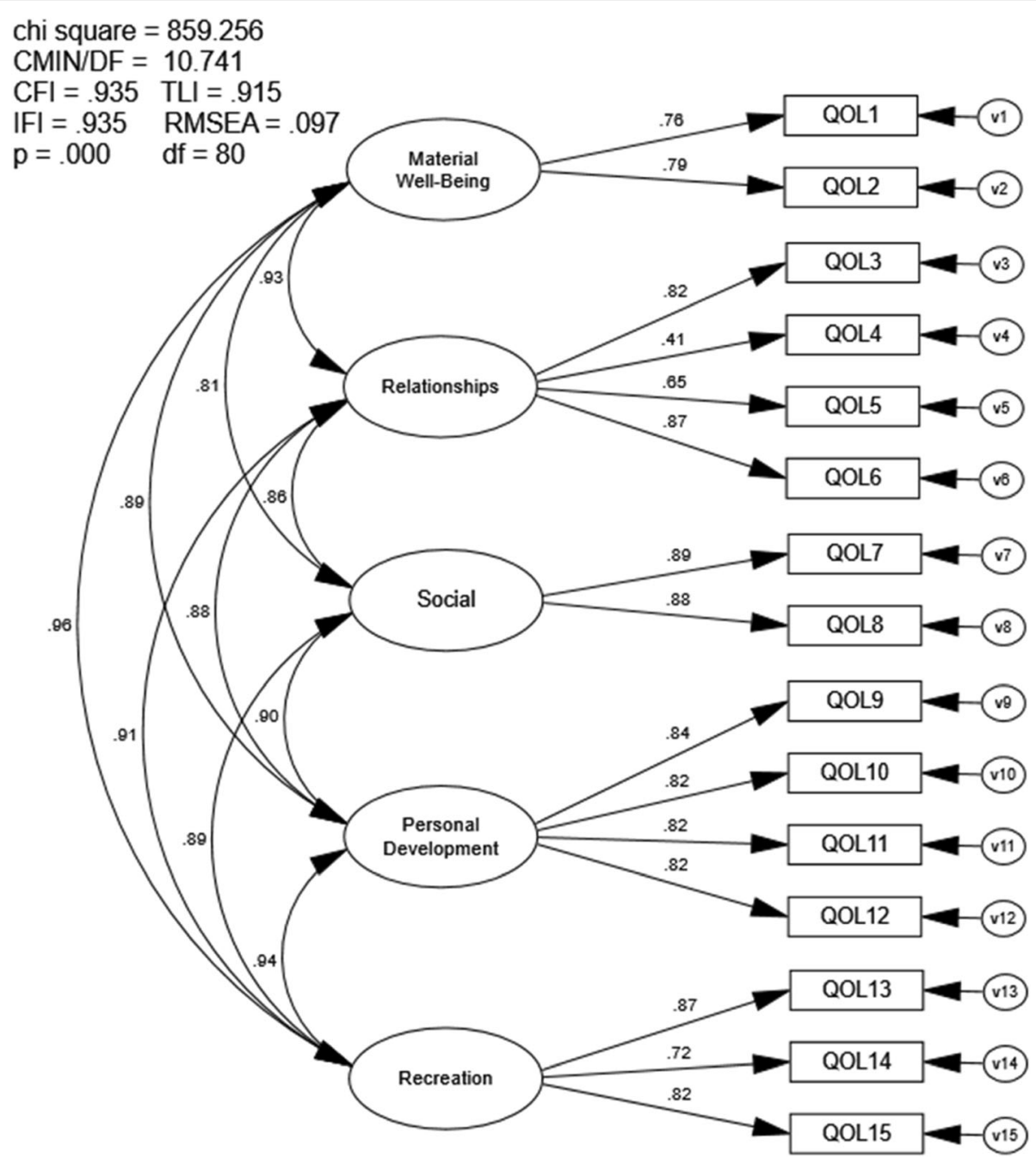

Fig. 2 First-Order Confirmatory Factor Analysis five-factor 15-item QOLS. Chi Sq = Chi Square (X2), CMIN/DF = the X2 / degrees of freedom ratio; $\mathrm{CFI}=$ Comparative Fit Index; TLI = Tucker-Lewis Index; IFI = Bollen's Incremental Fit Index; RMSEA = Root Mean Square Error of Approximation, $\mathrm{df}=$ degrees of freedom, $\mathrm{p}=$ alpha level

Because the five-item QOLS satisfied metric (equal loadings) invariance criteria, examining an equal latent QoL variance structure was warranted. Results indicated both the $\mathrm{CFI}_{\mathrm{DIFF}}$ and $\mathrm{X}^{2}$ DIFF non-invariant criteria were exceeded (Table 8). When variances were not constrained to be equal, the female subsample exhibited substantially more variability on latent QoL than did the male sub-sample (male variance $=0.47$, female variance $=1.46$.)

The scalar model (i.e., equal loadings and intercepts) exceeded the $X^{2}$ DIFF test criteria, and just exceeded the $\mathrm{CFI}_{\text {DIFF }}$ test criteria (Table 8), which suggested potential item-level bias between males and females. Follow-up analysis indicated Item \#2 exhibited slight bias (i.e., when Item \#2 was not restricted to be equivalent across both groups, the revised five-item model then met invariance criteria).

\section{Invariance testing physically active-healthy and physically active-injured subgroups}

From the full sample, the physically active-healthy $(n=$ $151)$ and physically active-injured $(n=470)$ subgroups were used for invariance testing. The initial model (configural) demonstrated very good model fit $(\mathrm{CFI}=.989$; $X^{2}=16.702$; RMSEA $=.033$; Table 9), indicating the basic five-item model structure was invariant across the PA-H and PA-I sub-groups. The metric model (i.e., equal loadings) also passed both the CFI $\mathrm{DIFF}_{\text {test }}$ and the $X^{2}$ DIFF test. The five-item QOLS metric invariance warranted testing of equal latent $\mathrm{QoL}$ variance. Both $\mathrm{CFI}_{\mathrm{DIFF}}$ 


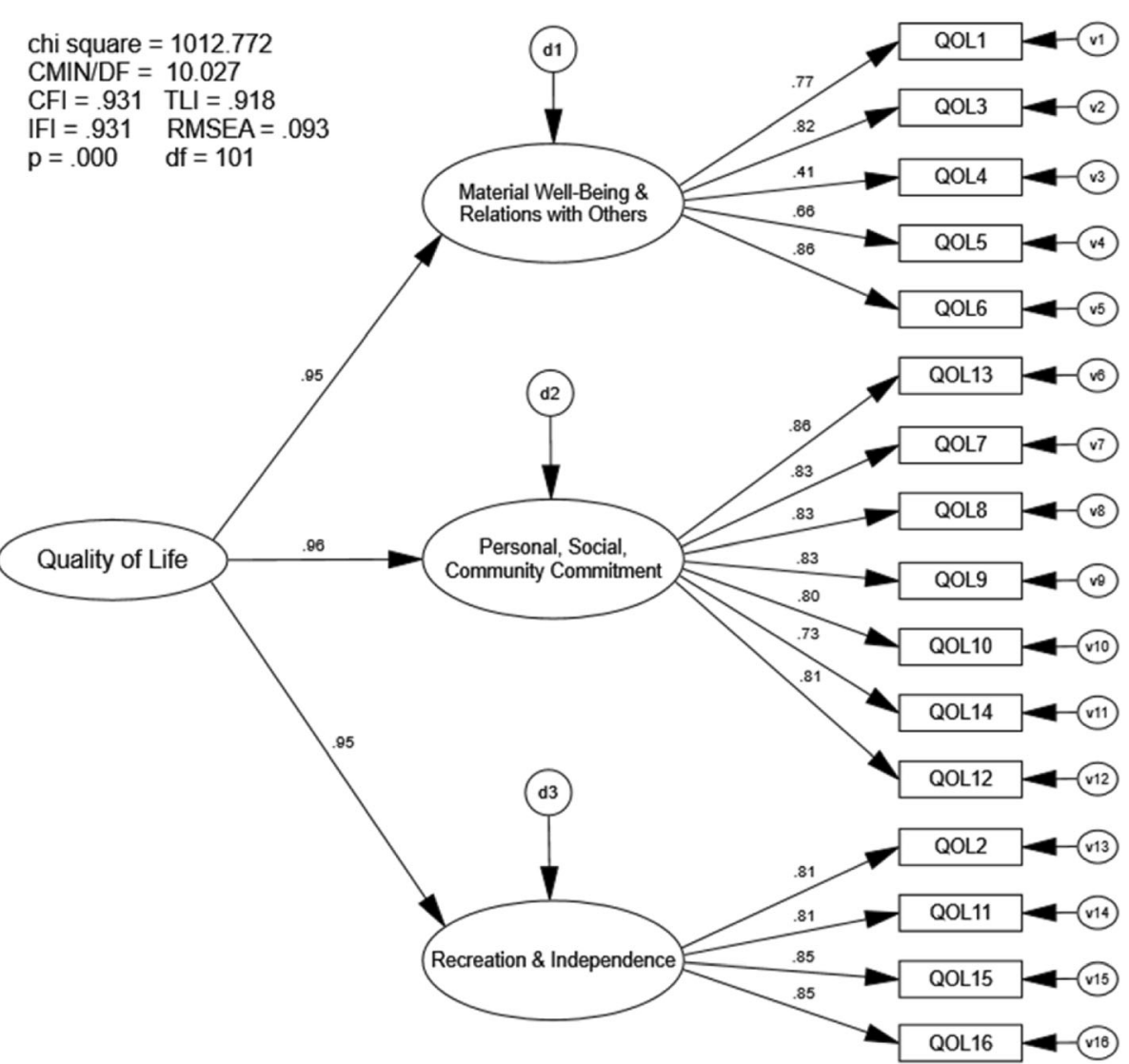

Fig. 3 Confirmatory Factor Analysis three-factor 16-item QOLS. Chi Sq = Chi Square (X2), CMIN/DF = the X2 / degrees of freedom ratio; CFI = Comparative Fit Index; TLI = Tucker-Lewis Index; IFI = Bollen's Incremental Fit Index; RMSEA = Root Mean Square Error of Approximation, $\mathrm{df}=$ degrees of freedom, $p=$ alpha level

and $X^{2}$ DIFF criteria were met (Table 9). Thus, both PA-H and PA-I sub-samples exhibited similar variability on the latent QOLS dimension.

The scalar model (i.e., equal loadings and intercepts) did not pass the CFI DIFF test or the $\chi^{2}$ DIFF test, suggesting item-level bias (Table 9). Follow-up analysis indicated Item \#2 exhibited substantial bias (i.e., when Item \#2 was not restricted to be equivalent across both groups, the revised five-item model met all measurement invariance criteria for these sub-groups).

\section{Invariance testing for physically active-healthy and osteoarthritis subgroups}

From the full sample, the physically active-healthy ( $n=$ $151)$ and osteoarthritis $(n=131)$ subgroups were used for invariance testing. The initial model (configural) demonstrated very good model fit $\left(\mathrm{CFI}=.986 ; X^{2}=15.941\right.$; RMSEA = .046; Table 10), indicating equal form of the five-item model for both groups. The metric model (i.e., equal loadings) passed both the $\mathrm{CFI}_{\mathrm{DIFF}}$ test and the $X^{2}$ DIFF test. Because the five-item QOLS satisfied metric model invariance criteria, an equal latent QoL variance model was warranted. Both $\mathrm{CFI}_{\text {DIFF }}$ and $\mathrm{X}^{2}$ DIFF noninvariant criteria were exceeded (Table 10). When variances were not constrained to be equal, the OA subsample exhibited substantially more variability on latent QoL than did PA-H group $(\mathrm{PA}-\mathrm{H}$ variance $=0.51, \mathrm{OA}$ variance $=1.40$.)

The scalar model (i.e., equal loadings and intercepts) did not pass the $C F I_{\text {DIFF }}$ test or the $X^{2}$ DIFF test, again suggesting item-level bias between health status subgroups (Table 10). When Item \#2 was not restricted to be equivalent across both groups, the revised five-item model met all measurement invariance criteria.

\section{Follow-up analysis on a proposed four-item QOLS}

Because the second item of the revised five-item QOLS was a consistent source of non-invariance and item-level bias for all subgroup analyses, invariance procedures were repeated after eliminating this item. Results are displayed in Table 11. In summary, a four-item version exhibited measurement invariance for all conditions and subgroups, except for the scalar invariance model when 


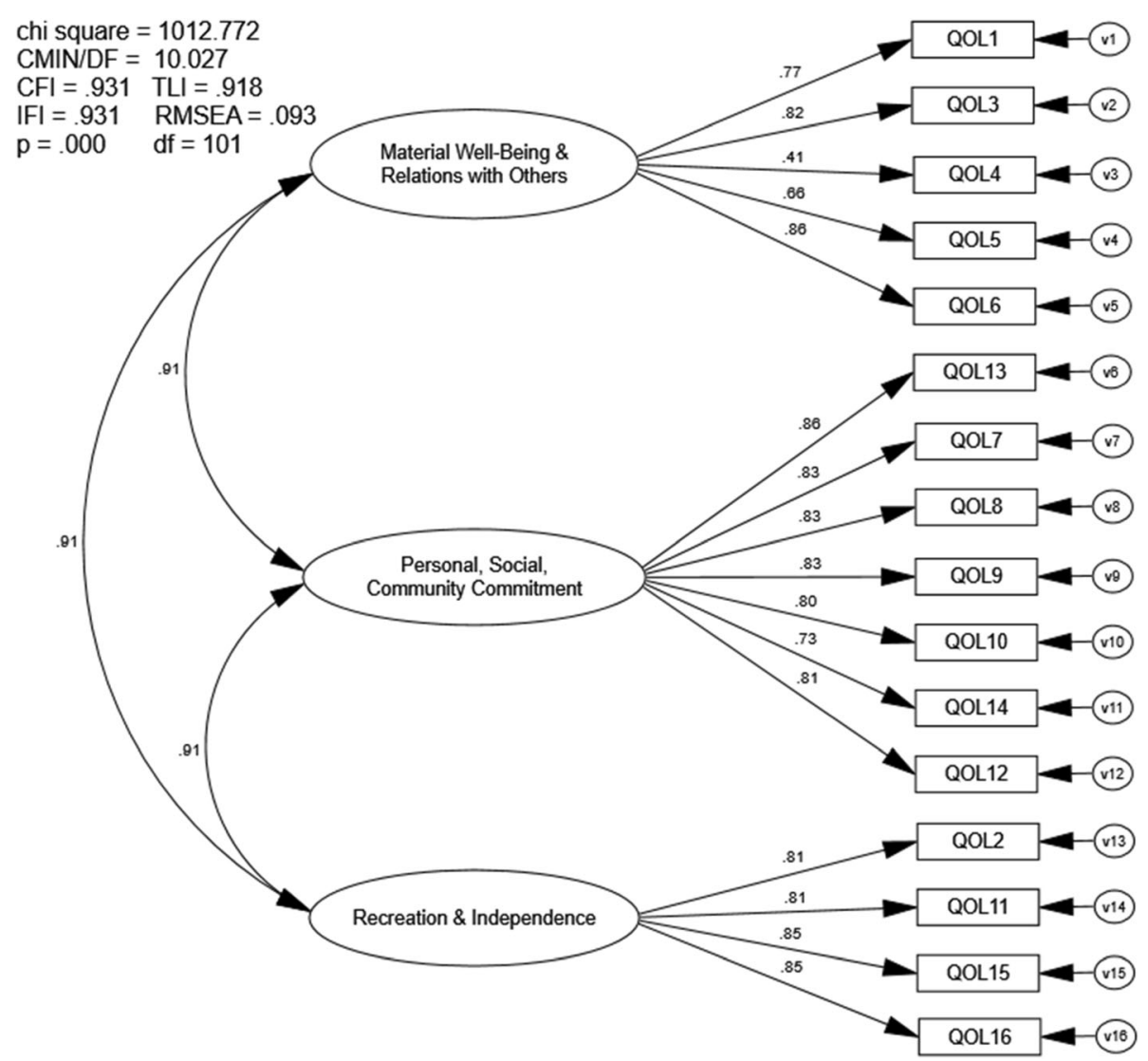

Fig. 4 First-Order Confirmatory Factor Analysis three-factor 16-item QOLS. Chi Sq = Chi Square (X2), CMIN/DF = the X2 / degrees of freedom ratio; $\mathrm{CFI}=$ Comparative Fit Index; TLI = Tucker-Lewis Index; IFI = Bollen's Incremental Fit Index; RMSEA = Root Mean Square Error of Approximation, $d f=$ degrees of freedom, $p=$ alpha level

Table 6 Initial exploratory factor analysis loadings $(n=518)$

\begin{tabular}{|c|c|c|}
\hline Item & Factor 1 & Factor 2 \\
\hline 1. "Material comforts home, food, conveniences, financial security..." & .584 & -.246 \\
\hline 2. "Health - being physically fit and vigorous..." & .279 & -.746 \\
\hline 3. "Relationships with parents, siblings \& other relatives - communicating, visiting, helping..." & .710 & -.139 \\
\hline 4. "Having and raising children..." & .530 & .162 \\
\hline 5. "Relationships with spouse or significant other..." & .668 & .051 \\
\hline 6. "Close friends..." & .756 & -.136 \\
\hline 7. "Helping and encouraging others, volunteering, giving advice..." & .821 & .007 \\
\hline 8. "Participating in organizations and public affairs..." & .791 & -.047 \\
\hline 9. "Learning - attending school, improving understanding, getting additional knowledge..." & .819 & -.013 \\
\hline 10. "Understanding yourself - knowing your assets and limitations - knowing what life is about..." & .840 & .016 \\
\hline 11. "Work - job or in home..." & .773 & -.096 \\
\hline 12. "Expressing yourself creatively..." & .818 & .050 \\
\hline 13. "Socializing - meeting other people, doing things, parties, etc." & .748 & -.176 \\
\hline 14. "Reading, listening to music, or observing entertainment..." & .700 & -.023 \\
\hline 15. "Participating in active recreation..." & .461 & -.542 \\
\hline 16. "Independence, doing for yourself..." & .664 & -.258 \\
\hline Cronbach's Alpha | Omega & $.95 \mid .95$ & $.88 \mid .89$ \\
\hline
\end{tabular}


Table 7 New proposed QOLS model $(n=518)$

\begin{tabular}{ll}
\hline Item & Factor 1 \\
\hline 11. "Work - job or in home..." & .814 \\
3. "Relationships with parents, siblings \& other relatives - communicating, visiting, helping..." & .758 \\
1. "Material comforts home, food, conveniences, financial security..." & .800 \\
2. "Health - being physically fit and vigorous..." & .830 \\
8. "Participating in organizations and public affairs..." & .750 \\
Cronbach's Alpha | Omega & $.89 \mid .89$ \\
\hline
\end{tabular}

comparing PA-H individuals to the OA sub-sample. For this comparison, Item \#3 exhibited biased responses.

As with the five-item scale, females reported higher levels of variability than did males when latent QoL was based on the four-item scale. The invariant scalar model results warranted comparison of reported levels of QoL between males and females. Based on the four-item QOLS, females reported higher levels of QoL than did males. Likewise, consistent with the five-item scale, the four-item QOLS exhibited no difference in variability on latent QoL scores when PA-H individuals were compared to the PA-I sample. Further, there was not any apparent difference of average levels of QoL when these samples were compared using the four-item scale. Again, consistent with the five-item QOLS results, the OA subsample exhibited substantially more variability than did the PA-H sub-sample. The non-invariant scalar results precluded comparison of mean levels of QoL between these samples.

\section{Correlation analyses}

The five-item QOLS was highly correlated (covariance latent variable model $r=1.0, R^{2}=1.0$; bivariate cumulative score $r=.96, R^{2}=.92$ ) with the 16 -item QOLS. The four-item QOLS was also highly correlated (covariance latent variable model $r=1.0, \mathrm{R}^{2}=1.0$; bivariate cumulative score $\left.r=.95, R^{2}=.90\right)$ with the 16 -item QOLS.

\section{Discussion}

In the present study, we aimed to identify if the proposed factor structure of previously published QOLS versions were psychometrically sound using contemporary CFA and structural equation modeling procedures in a large, heterogeneous sample. The CFA approach was used to more rigorously examine the QOLS for use in clinical practice and research [16]. We also used EFA to identify an alternative, more parsimonious structure for the QOLS. The modified QOLS was further evaluated using CFA and CFA-based invariance testing to determine if the more parsimonious QOLS measurement model better met psychometric measurement recommendations. The findings of our study suggest the original QOLS versions do not meet recommended measurement properties, and thus, challenge the appropriateness of using the QOLS as a valid multidimensional QoL assessment tool.

\section{Confirmatory factor analysis of the Quality of Life Scale} Prior claims of validity of the QOLS [10-15] are not supported by the inconsistent factor content reported in

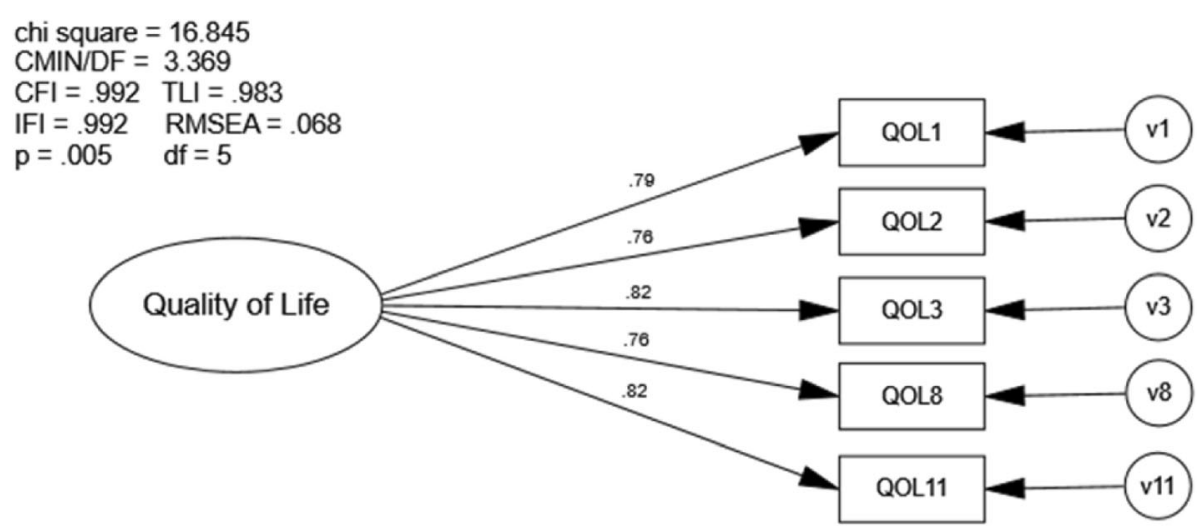

Fig. 5 Covariance Model of Modified QOLS. Chi Sq = Chi Square (X2), CMIN/DF = the X2 / degrees of freedom ratio; CFI = Comparative Fit Index; $\mathrm{TLI}=$ Tucker-Lewis Index; IFI = Bollen's Incremental Fit Index; RMSEA = Root Mean Square Error of Approximation, $\mathrm{df}=$ degrees of freedom, $\mathrm{p}=$ alpha level 


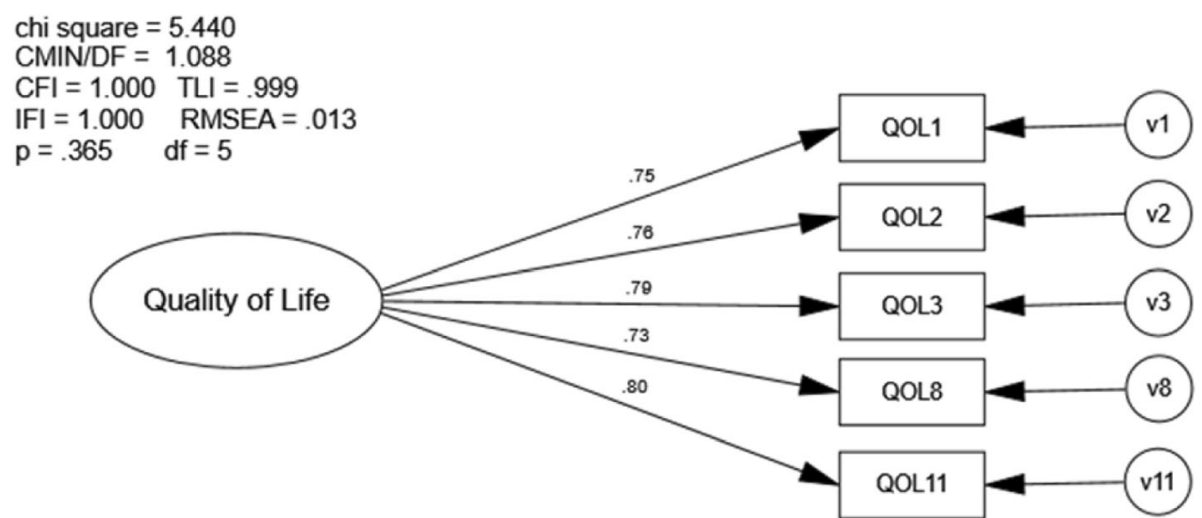

Fig. 6 Confirmatory Factor Analysis of Modified QOLS. Chi Sq = Chi Square (X2), CMIN/DF = the X2 / degrees of freedom ratio; CFI = Comparative Fit Index; TLI = Tucker-Lewis Index; IFI = Bollen's Incremental Fit Index; RMSEA = Root Mean Square Error of Approximation, $d f=$ degrees of freedom, $p=$ alpha level

previously published literature. Furthermore, neither the five-factor structure nor the three-factor structure met recommended CFA psychometric properties in this study. For example, high correlation values between latent variables in both measurement models suggest the presence of substantial multicollinearity among the claimed distinct dimensions $[17,19]$. These characteristics, combined with inadequate overall model fit of the CFAs and potential multicollinearity of the proposed sub-dimensions (i.e., high latent variable correlations), contradict previously assumed validity of the multidimensionality of the QOLS [10-15]. Without a psychometrically sound measurement model (either 15or 16-item version), there was no justification for pursing the invariance analyses of the original QOLS scales. However, our results did warrant a specification search for a more psychometrically desirable solution using QOLS items [19].

\section{Psychometric analysis of a modified Quality of Life Scale} A single factor, five item solution, representing overall QoL, emerged from our analysis. The modified scale included at least one item from four of the five originally proposed factors (i.e., PMWB, REL, SCC, PDF) in the 15 -item version, but no items from the original
'Recreation' factor. Of the originally proposed threefactor, 16-item scale, the new version included at least one item from each factor (i.e., $\mathrm{RMW}=2, \mathrm{HF}=2$, PSCC $=1$ ). Although all five originally proposed factors were not represented in the modified scale [10], it still comprised a wide variety of items that represented different aspects of the theorized construct of QoL [10].

The new five-item QOLS was then subjected to confirmatory analysis. Statistically, the new five-item scale exceeded a-priori guidelines for model fit [17], offering encouraging results for the possibility of using five items to adequately measure overall QoL. The summative scores on the new five-item scale and original 16-item scale were highly correlated $(r=.96)$, indicating that most of the variance $\left(R^{2}=.92\right)$ in participant responses from the 16-item scale was accounted for using only five items. This finding reiterates the item redundancy issues observed in the original model, and further suggests that the included five items assess the proposed QoL construct as well as all sixteen items.

Unfortunately, follow-up invariance testing of the modified QOLS by sub-groups (i.e., sex and health status) produced mixed results. As evidenced by the configural invariance models, the basic five-item structure did hold up in form for the sub-groups examined.

Table 8 Goodness-of-fit indices for the measurement invariance analyses across sex

\begin{tabular}{|c|c|c|c|c|c|c|c|}
\hline & $x^{2}$ & $\mathrm{df}$ & $x_{\text {diff }}^{2}\left(\mathrm{df}_{\text {diff }}\right)$ & $\mathrm{CFI}$ & $\mathrm{CFI}_{\text {diff }}$ & TLI & RMSEA \\
\hline Males $(n=387)$ & 15.58 & 5 & - & 0.987 & - & 0.973 & 0.074 \\
\hline Females $(n=641)$ & 7.65 & 5 & - & 0.998 & - & 0.997 & 0.029 \\
\hline Model A (equal form) & 23.25 & 10 & - & 0.994 & - & 0.989 & 0.036 \\
\hline Model B (equal loadings) & 31.45 & 14 & $8.20(4)$ & 0.993 & 0.001 & 0.99 & 0.035 \\
\hline Model C (equal factor variances) & 58.63 & 15 & $35.39(5)$ & 0.982 & 0.012 & 0.976 & 0.053 \\
\hline Model D (equal indicator intercepts) & 60.31 & 18 & $37.07(8)$ & 0.982 & 0.012 & 0.98 & 0.048 \\
\hline Model E (equal latent means) & 148.24 & 19 & $124.99(9)$ & 0.946 & 0.048 & 0.943 & 0.081 \\
\hline
\end{tabular}


Table 9 Goodness-of-fit indices for the measurement invariance analyses across physically active-healthy and physically activeinjured subgroups

\begin{tabular}{|c|c|c|c|c|c|c|c|}
\hline & $x^{2}$ & $\mathrm{df}$ & $x_{\text {diff }}^{2}\left(\mathrm{df}_{\text {diff }}\right)$ & $\mathrm{CFI}$ & $\mathrm{CFI}_{\text {diff }}$ & $\mathrm{TLI}$ & RMSEA \\
\hline $\mathrm{PA}-\mathrm{H}(n=151)$ & 9.87 & 5 & - & 0.973 & - & 0.947 & 0.081 \\
\hline PA-I $(n=470)$ & 6.80 & 5 & - & 0.996 & - & 0.991 & 0.028 \\
\hline Model A (equal form) & 16.70 & 10 & - & 0.989 & - & 0.977 & 0.033 \\
\hline Model B (equal loadings) & 21.31 & 14 & 4.61(4) & 0.988 & $<0.001$ & 0.982 & 0.029 \\
\hline Model C (equal factor variances) & 21.55 & 15 & $4.84(5)$ & 0.989 & $<0.001$ & 0.985 & 0.027 \\
\hline Model D (equal indicator intercepts) & 42.36 & 18 & $25.66(8)$ & 0.959 & 0.03 & 0.954 & 0.047 \\
\hline Model E (equal latent means) & 44.37 & 19 & $27.67(9)$ & 0.957 & 0.032 & 0.955 & 0.046 \\
\hline
\end{tabular}

Furthermore, the metric invariance models demonstrated that subgroups exhibited a consistent covariance structure among the five items. These results provide support for potentially using the five-item QOLS version to examine relationships of QoL with other constructs [17]. However, the five-item scalar measurement models failed to provide evidence supporting valid use of the new scale to compare subgroup levels (i.e. "amounts") of QoL. The prime contributor to this measurement bias appeared to be Item \#2, which taps into physical health status. Upon reflection, these results are not surprising given that two of the three subgroup analyses examined were comparisons of physically active healthy individuals to those with a physical injury or physical activity limiting condition.

Reducing the scale even further by removing the problematic Item \#2 resulted in a more psychometrically sound scale that appears to measure a consistent construct for some of the subgroups tested. However, the further abbreviated four-item version still failed the scalar invariance test for comparing the PA-H group to the OA group. Thus, use of this scale would only be appropriate for examining differences in relationships of QoL with other constructs without comparing actual levels of QoL for certain subgroups. Further, it can be argued that removing the only indicator representing physical health might represent a meaningful alteration of what underlying construct is being assessed in groups suffering from a pathology affecting physical health.

\section{Implementation in clinical practice and research}

Assessing patient reported QoL is an important component of healthcare research and practice; however, we do not recommend assessment and interpretation of QoL using the 15- or 16-item QOLS versions. Examining the items beyond the statistical analysis of the scale reveals inherent design flaws that we believe contributed to the poor psychometric properties of the scale. In particular, concerns arose regarding redundant, double-barreled (i.e., asking about two or more ideas at once) items and whether the response Likert scale consistently matched question structure. Double-barreled questions are problematic because a respondent does not know which part of the item to respond to when selecting their Likert score. Thus, the use of doublebarred question causes confusion and inconsistent responses among participants, which results in subsequent analysis complications [26]. When examining the original QOLS items [10], we noted that many questions were double-barreled or more extreme (e.g., lists of several activities, etc.) [26].

Table 10 Goodness-of-fit indices for the measurement invariance analyses across physically active-healthy and osteoarthritis subgroups

\begin{tabular}{|c|c|c|c|c|c|c|c|}
\hline & $x^{2}$ & df & $x_{\text {diff }}^{2}\left(\mathrm{df}_{\text {diff }}\right)$ & CFI & $\mathrm{CFI}_{\text {diff }}$ & TLI & RMSEA \\
\hline$\overline{P A-H}(n=151)$ & 9.87 & 5 & - & 0.973 & - & 0.947 & 0.051 \\
\hline $\mathrm{OA}(\mathrm{n}=131)$ & 6.07 & 5 & - & 0.996 & - & 0.991 & 0.041 \\
\hline Model A (equal form) & 15.94 & 10 & - & 0.986 & - & 0.972 & 0.046 \\
\hline Model B (equal loadings) & 18.83 & 14 & 2.89 & 0.989 & $<0.001$ & 0.984 & 0.035 \\
\hline Model C (equal factor variances) & 42.63 & 15 & 26.69 & 0.936 & 0.05 & 0.914 & 0.081 \\
\hline Model D (equal indicator intercepts) & 101.30 & 18 & 85.36 & 0.806 & 0.18 & 0.784 & 0.129 \\
\hline Model E (equal latent means) & 216.57 & 19 & 200.63 & 0.54 & 0.446 & 0.515 & 0.193 \\
\hline
\end{tabular}


Table 11 Goodness-of-fit indices for measurement invariance analyses - four-item model across sex and health status subgroups

\begin{tabular}{|c|c|c|c|c|c|c|c|}
\hline & $x^{2}$ & df & $x_{\text {diff }}^{2}\left(\mathrm{df}_{\text {diff }}\right)$ & $\mathrm{CFI}$ & $\left.C F\right|_{\text {diff }}$ & TLI & RMSEA \\
\hline Males $(n=387)$ & 4.31 & 2 & - & 0.996 & - & 0.988 & 0.055 \\
\hline Females $(n=641)$ & 5.13 & 2 & - & 0.997 & - & 0.992 & 0.049 \\
\hline Model A (equal form) & 9.44 & 4 & - & 0.997 & - & 0.991 & 0.036 \\
\hline Model B (equal loadings) & 10.54 & 7 & $1.10(3)$ & 0.998 & $<0.001$ & 0.996 & 0.022 \\
\hline Model C (equal factor variances) & 41.57 & 8 & $32.13(4)$ & 0.981 & 0.016 & 0.971 & 0.064 \\
\hline Model D (equal indicator intercepts) & 14.41 & 10 & $4.97(6)$ & 0.997 & $<0.001$ & 0.997 & 0.021 \\
\hline Model E (equal latent means) & 86.83 & 11 & 77.39(7) & 0.956 & 0.041 & 0.952 & 0.082 \\
\hline $\mathrm{PA}-\mathrm{H}(n=151)$ & 7.30 & 2 & - & 0.965 & - & 0.895 & 0.133 \\
\hline PA-I $(n=470)$ & 2.83 & 2 & - & 0.997 & - & 0.992 & 0.03 \\
\hline Model A (equal form) & 10.16 & 4 & - & 0.987 & - & 0.96 & 0.05 \\
\hline Model B (equal loadings) & 12.93 & 7 & $2.78(3)$ & 0.987 & $<0.001$ & 0.978 & 0.037 \\
\hline Model C (equal factor variances) & 13.49 & 8 & $3.34(4)$ & 0.988 & 0.001 & 0.982 & 0.033 \\
\hline Model D (equal indicator intercepts) & 14.59 & 10 & $4.43(6)$ & 0.99 & 0.003 & 0.98 & 0.027 \\
\hline Model E (equal latent means) & 15.03 & 11 & $4.88(7)$ & 0.991 & 0.004 & 0.99 & 0.024 \\
\hline $\mathrm{PA}-\mathrm{H}(n=151)$ & 7.30 & 2 & - & 0.965 & - & 0.895 & 0.133 \\
\hline $\mathrm{OA}(n=131)$ & 1.43 & 2 & - & 1 & - & 1.01 & 0 \\
\hline Model A (equal form) & 8.73 & 4 & - & 0.986 & - & 0.957 & 0.065 \\
\hline Model B (equal loadings) & 11.29 & 7 & $2.56(3)$ & 0.987 & 0.001 & 0.978 & 0.047 \\
\hline Model C (equal factor variances) & 34.33 & 8 & $25.60(4)$ & 0.921 & 0.065 & 0.881 & 0.108 \\
\hline Model D (equal indicator intercepts) & 24.16 & 10 & $15.43(6)$ & 0.957 & 0.029 & 0.949 & 0.071 \\
\hline Model E (equal latent means) & 105.22 & 11 & $96.50(7)$ & 0.717 & 0.269 & 0.691 & 0.175 \\
\hline
\end{tabular}

Further, the Likert scale used for the QOLS is bipolar (i.e., has a negative and positive end) which potentially creates multiple problems for participant interpretation. First, the endpoints are "terrible" and "delighted," and these descriptors may not be seen as "opposites," which is recommended when using bipolar scales [26]. Second, the 1-7 scale does not have a neutral point, even though the "terrible" to "delighted" scale theoretically does [26]. Third, the verbiage of the scale options (i.e., "terrible" to "delighted") does not match the instructions given or follow an expected sequential order for respondents [26]. A more effective Likert scale, following contemporary survey recommendations may be one ranging from -3 to +3 that included similar wording on either end [26]. The item and Likert scale design issues may explain in part why the factor structure was so inconsistent across multiple samples in the literature [10-15], as well as the present study.

Inherent design flaws, as well as the concerns identified during CFA, indicate the original QOLS are not fit for use in clinical practice or research in their current form. The modified scales met initial testing standards, but the invariance testing results indicate caution is warranted when using the scales. At minimum, researchers and clinicians should be careful when interpreting group comparisons of QoL between subgroups in any investigation using these QOLS items as indicators of QoL. Because the evidence does not suggest the original or modified QOLS versions meet all contemporary recommendations (e.g., CFA fit indices recommendations, invariance testing recommendations, etc.), it would be imprudent to recommend the scale to accurately measure QoL, or changes in patient-perceived QoL, across various populations. Instead, we recommend either: 1) developing a new instrument to adequately assess all aspects of QoL, 2) choosing another existing QoL instrument and performing the necessary analysis to establish the psychometric properties of the scale meet current recommendations, or 3) identify an instrument that has met CFA and invariance guidelines and is ready for implementation in research and clinical practice.

\section{Limitations and future research}

While the present study has confirmed the lack of factorial validity of the QOLS, there are still limitations to consider. The five-item modified QOLS EFA and covariance model was assessed with a cross-validation sample to confirm the proposed model held in a new sample. However, the responses used for the cross-validation procedures were from a sample of participants who responded to all 16 items of the QOLS. Thus, it is 
possible that the responses to the five items were influenced by the other items not included in the final model. Therefore, further testing is needed to confirm the model fit of the modified QOLS when participants are only provided with those five items in the scale. Further, while we had a large and diverse sample, we did not conduct long-term follow-up or compare results with another criterion scale. Because of the study design, we could not perform test-retest reliability, perform longitudinal invariance testing, or establish scale responsiveness.

Assessing QoL is a vital component of providing quality patient care. Therefore, future research should aim to define QoL in a concise and universal manner, as the inconsistency of this definition appears to be one of the major obstacles in developing an adequate instrument. After a definition has been established, future research should identify or create an instrument that is psychometrically sound and can be used effectively in research and clinical practice. Finally, researchers should collect longitudinal data in diverse populations (e.g., pediatric, geriatric, injured, healthy, physically active, sedentary, etc.) to allow for the completion of all necessary analyses to establish scale reliability and validity.

\section{Conclusions}

The proposed construct validity of 15- and 16-item multidimensional QOLS versions was not substantiated by the findings in our study. Although our analyses identified a modified-QOLS that appeared to be a more psychometrically sound instrument, the modified version exhibited bias at the item level. The modified QOLS might be useful for addressing a limited set of associative research questions within certain sub-group populations. However, given its inconsistent psychometric properties across all sub-groups, combined with potential item design flaws and incomplete psychometric testing, we cannot recommend the modified version for widespread use by clinicians or researchers at this time. The need to measure QoL remains an important concept in healthcare, but improved assessment tools validated using contemporary technique are necessary to ensure the instrument is valid for use with various patient populations and subgroups.

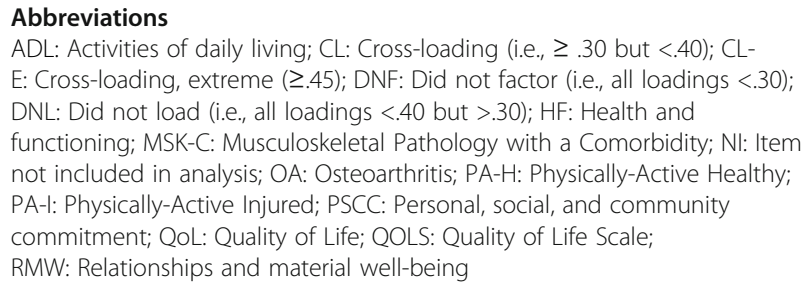

\section{Authors' contributions}

AJR - data analysis/interpretation, manuscript drafting, revisions, final edits/ approval.RTB - concept/design, data acquisition, data analysis/interpretation, manuscript drafting, revisions, final edits/approval.MPC - data analysis/ interpretation, manuscript drafting, revisions, final edits/approval.SWC - data interpretation, manuscript drafting, revisions, final edits/approval.MAP concept/design, data analysis/interpretation, manuscript revisions, final edits/ approval. The author(s) read and approved the final manuscript.

\section{Funding}

Not applicable.

\section{Availability of data and materials}

Datasets used and analyzed are available from the corresponding author upon reasonable request.

\section{Ethics approval and consent to participate}

Research was conducted in accordance with the Declaration of Helsinki and was approved by the University of Idaho Institutional Review Board (Project \# 16-149).

\section{Consent for publication}

Not applicable.

\section{Competing interests}

The authors declare that they have no competing interests.

\section{Author details}

${ }^{1}$ University of Idaho, 875 Perimeter Drive MS2401, Moscow, ID 83844, USA. ${ }^{2}$ California State University Dominguez Hills, 1000 E. Victoria Street, Carson, California 90747, USA.

Received: 4 April 2019 Accepted: 11 February 2020

\section{References}

1. Anderson KL, Burckhardt CS. Conceptualization and measurement of quality of life as an outcome variable for health care interventions and research. J Adv Nurs. 1999;29(2):298-306.

2. Morgan ML. Classics of Moral and political theory. 1st ed. Indianapolis, IN: Hackett Publishing Company; 1992.

3. Berzon RA, Donnelly MA, Simpson RL Jr, Simeon GP, Tilson HH. Quality of life bibliography and indexes: 1994 update. Qual Life Res. 1995;4(6):547-69.

4. Ferrans CE, Powers MJ. Quality of life index: development and psychometric properties. Adv Nurs Sci. 1985;8(1):15-24.

5. Patrick DL, Danis M, Southerland LI, Hong G. Quality of life following intensive care. J Gen Intern Med. 1988;3(3):218-23.

6. Ferrans CE. Quality of life: conceptual issues. Semin Oncol Nurs. 1990;6(4): 248-54.

7. Smith KW, Avis NE, Assmann SF. Distinguishing between quality of life and health status in quality of life research: a meta-analysis. Qual Life Res. 1999; 8(5):447-59.

8. Burckhardt CS, Anderson KL. The quality of life scale: reliability, validity, and utilization. Health Qual Life Out. 2003;1:60.

9. Gill TM, Feinstein AR. A critical appraisal of the quality of life measurements, JAMA. 1994;272(8):619-26.

10. Burckhardt CS, Anderson KL, Archenholtz B, Hägg O. The Flanagan quality of life scale: evidence of construct validity. Health Qual Life Out. 2003;1:59.

11. Burckhardt CS, Archenholtz B, Bjelle A. Measuring quality of life of women with rheumatoid arthritis or systemic lupus erythematosus: a Swedish version of the quality of life scale (QOLS). Scand J Rheumatol. 1992;21(4): 190-5.

12. Liedberg GM, Burckhardt CS, Henriksson CM. Validity and reliability testing of the quality of life scale, Swedish version in women with fibromyalgia statistical analyses. Scand J Caring Sci. 2005;19(1):64-70.

13. Wahl A, Burckhardt CS, Wiklund I, Hanestad BR. The Norwegian version of the quality of life scale (QOLS-N): a validation and reliability study in patients suffering from psoriasis. Scand J Caring Sci. 1998;12(4):215-22.

14. Offenbächer M, Sauer S, Kohls N, Waltz M, Schoeps P. Quality of life in patients with fibromyalgia: validation and psychometric properties of the German quality of life scale (QOLS-G). Rheumatol Int. 2012;32(10):3243-52. 
15. Latorre-Román PA, Martínez-Amat A, Martínez-López E, Moral Á, Santos MA, Hita-Contreras F. Validation and psychometric properties of the Spanish version of the quality of life scale (QOLS) in patients with fibromyalgia. Rheumatol Int. 2014;34(4):543-9.

16. Bryant FB, Yarnold PR. Principal-components analysis and exploratory and confirmatory factor analysis. In: Grimm LG, Yarnold PR, editors. Reading and understanding multivariate statistics. Washington, DC, United States: American Psychological Association; 1995. p. 99-136.

17. Kline RB. Principles and practice of structural equation modeling. 4th ed. New York, NY: The Guilford Press; 2015.

18. Leech NL, Barret KC, Morgan GA. IBM SPSS for intermediate statistics: use and interpretation. 5th ed. New York, NY: Routledge; 2015.

19. Brown TA. Confirmatory factor analysis for applied research. 2nd ed. New York, NY: The Guilford Press; 2015.

20. Vela LI, Denegar CR. The disablement in the physically active scale, part II: the psychometric properties of an outcome scale for musculoskeletal injuries. J Athl Train. 2010;45(6):630-41.

21. Strong J, Unruh AM, Wright A, Baxter GD. Pain: a textbook for therapists. Edinburgh, Scotland: Churchill Livingstone; 2002. p. 425-33.

22. US Department of Health and Human Services. 2008 physical activity guidelines for Americans. Washington, DC, United States: US Department of Health and Human Services; 2008 .

23. Hu LT, Bentler PM. Cutoff criteria for fit indexes in covariance structural analysis: conventional criteria versus new alternatives. Struct Eq Modeling. 1999;6:1-55

24. Schweizer K. On the changing role of Cronbach's a in the evaluation of the quality of a measure. Eur J Psychol Assess. 2011;27(3):143-4.

25. Ware J Jr, Kosinski M, Keller SD. A 12-item short-form health survey: construction of scales and preliminary tests of reliability and validity. Med Care. 1996;34(3):220-33.

26. Dillman DA, Smyth JD, Christian LM. Internet, phone, mail, and mixed-mode surveys: the tailored design method. 4th ed. Hoboken, NJ: Wiley \& Sons; 2014

\section{Publisher's Note}

Springer Nature remains neutral with regard to jurisdictional claims in published maps and institutional affiliations.

Ready to submit your research? Choose BMC and benefit from:

- fast, convenient online submission

- thorough peer review by experienced researchers in your field

- rapid publication on acceptance

- support for research data, including large and complex data types

- gold Open Access which fosters wider collaboration and increased citations

- maximum visibility for your research: over $100 \mathrm{M}$ website views per year

At $\mathrm{BMC}$, research is always in progress.

Learn more biomedcentral.com/submissions 